\title{
A Fragment of an Early Book of Two Ways on the Coffin of Ankh from Dayr al-Barshā (B4B)
}

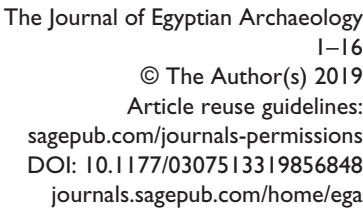

(SAGE

\author{
Harco Willems \\ $\mathrm{KU}$ Leuven, Belgium
}

\begin{abstract}
Remains of the early Middle Kingdom coffin of a lady called Ankh (B4B) contain parts of the earliest now known version of the Book of Two Ways. The fragment published here retains parts of CT spells 1128 and 1130. The article discusses the problems involved in the publication of this particular source, and in reading the incised hieratic signs of this source. Also, the article places the version of source B4B within the context of the editorial development of the Book of Two Ways.

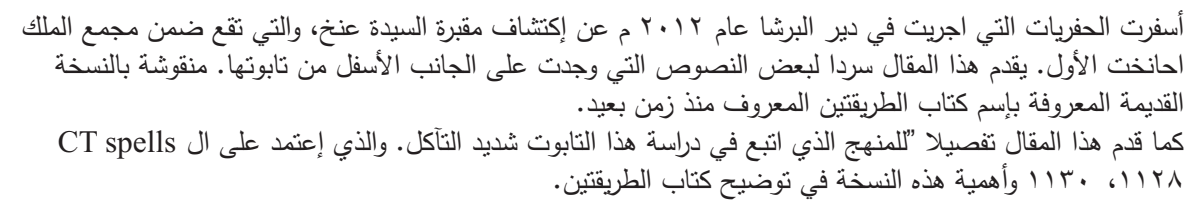

\section{Keywords}

Ankh, Book of Two Ways, coffin B4B, Coffin Texts, Dayr al-Barshā

In March/April 2012, the Dayr al-Barshā project of KU Leuven excavated burial shaft $17 \mathrm{~K} 85 / 1 \mathrm{~B}$ at the site. This is one of the five shafts of the early Middle Kingdom tomb complex of the nomarch Ahanakht I. The excavations, mostly carried out by Gina Criscenzo-Laycock, but with assistance of Hanne Creylman and the author, brought to light remains that at first suggested the tomb had been thoroughly rifled. Careful documentation of the find location soon made it clear, however, that many non-organic finds were still in their original position. This even made it possible to determine the order in which the objects had been placed in the burial chamber, enabling a reconstruction of the scenario of the funeral. ${ }^{1}$

However, the organic remains had sustained severe damage, owing to both repeated looting and the effects of fungi. The robbers had evidently ripped off planks in their search

\footnotetext{
1 H. Willems, 'The Tomb of Djehutinakht (III?) at Dayr al-Barshā', Egyptian Archaeology 44 (2014), 36-8; H. Willems, 'Die Grabkammer des Djehutinakht (I.?) in Dayr al-Barshā Methodologische Aspekte der Rekonstruktion des Ablaufs des Bestattungsrituals anhand eines neuentdeckten Beispiels', in A. H. Pries (ed.), Die Variation der Tradition: Modalitäten der Ritualadaptation im alten Ägypten. Akten des Internationalen Symposions vom 25.-28. November in Heidelberg (OLA 240; Leuven, 2016), 133-70.
}

for treasure, throwing the fragments through the burial chamber. Given the very brittle condition of the wood, during the excavation the excavators could do no more than carefully wrap the hundreds of pieces in protective covers made of wood and plastic foam, without the possibility to study them in more than a superficial fashion. In subsequent seasons, between 2013 and 2017, our conservator Mohamed Sayyid carefully unpacked, stabilised, and where possible restored the pieces, a process that still has not been completely finished. Since proper recording is impossible before the very fragile items have been treated, we are only now reaching the point where we can begin to reconstruct the coffin(s). Meanwhile, we have also been able to determine that the tomb owner possessed a canopic box, a fact that had passed unnoticed when the jumble of disintegrated wood was removed in 2012. We anticipate that we will finish the documentation of the complete burial in $2019 .{ }^{2}$

\footnotetext{
${ }^{2}$ A monograph on this tomb shaft, by Gina Criscenzo-Laycock and the present author, is in preparation.
}

\section{Corresponding author:}

Harco Willems, Department of Archaeology, KU Leuven,

Blijde-Inkomststraat 2I - Box 3318, 3000 Leuven, Belgium.

Email: harco.willems@kuleuven.be 
Although it was impossible during the excavations to study the textual material in detail, our attention was caught by some well-preserved wood fragments inscribed with Coffin Texts (CT), which clearly designated the male coffin owner as Djehutinakht. We initially assumed this was the name of the person originally buried in shaft $17 \mathrm{~K} 85 / 1 \mathrm{~B}$, and tentatively identified him with the nomarch Djehutinakht I, the predecessor of Ahanakht I (the latter being a contemporary of king Mentuhotep II). ${ }^{3}$ However, it has now become clear that the fragments in question were found in fill that included recently moved material. On the in situ part of the coffin bottom presented in this article, however, the deceased is consistently referred to as $千 \ominus$. The same name occurs on many other coffin fragments found in the chamber. Moreover, the name is frequently followed by the demonstrative pronoun $t n$; in other places the personal pronoun $=s$ is used to refer to the owner. Therefore, it is now certain that the tomb owner was not Djehutinakht I, but a hitherto unknown lady called Ankh. ${ }^{4}$ The almost complete bone collection of a female found in the secondary shaft fill may be hers. ${ }^{5}$

This article focuses on the only part of the coffin decoration that was found entirely in situ: the bottom (fig. 1). By carefully removing the dirt and collapsed coffin parts, it could be revealed almost in its entirety (fig. 2). In most places, the surface had unfortunately disappeared, but near the foot end, a large area was preserved. Because this surface was brittle, it was unwise to clean the area entirely, as this would displace parts that were preserved more or less in their original locations, with little chance of them being correctly placed back. As a result, the excavation photographs, taken just before the bottom was removed, show numerous areas where dust or concentrations of small wood fragments obscure the decoration. These images are therefore only partly satisfactory, but they at least show all pieces still in their original locations (fig. 3). Subsequently the bottom was lifted, but owing to its state this had to be done in separate pieces. We took care, however, to position the fragments to the extent possible in their correct arrangement, and when the pieces were taken from their protective cover in the spring of 2017, most were still in their correct relative locations (fig. 4). It was already clear during the excavation that between the large south-eastern group A and the smaller south-western group B there was a damaged zone (figs 1 and 3). Although all pieces were kept together with the larger fragments, it proved impossible in the laboratory to fill this gap. The easternmost part A is the largest, and it

\footnotetext{
${ }^{3}$ In the first article referred to in note 1 , this person was inadvertently referred to as 'Djehutinakht (III?)'.

${ }^{4}$ Arguably, a block discovered by Newberry in what he called tomb 6, and referring to a 'Djehutinakht, whom Ankh ... conceived', may refer to this woman (F. L1. Griffith and P. E. Newberry, El Bersheh, II [London, 1894], 36). For the likelihood that this fragment derives from the tomb complex of Ahanakht I, see H. Willems, The Djoser Complex as a Source of Inspiration for the Decoration of Private Coffins in the Middle Kingdom (in press).

${ }^{5}$ I express my gratitude to Lana Williams for the anthropological analysis of these remains.
}

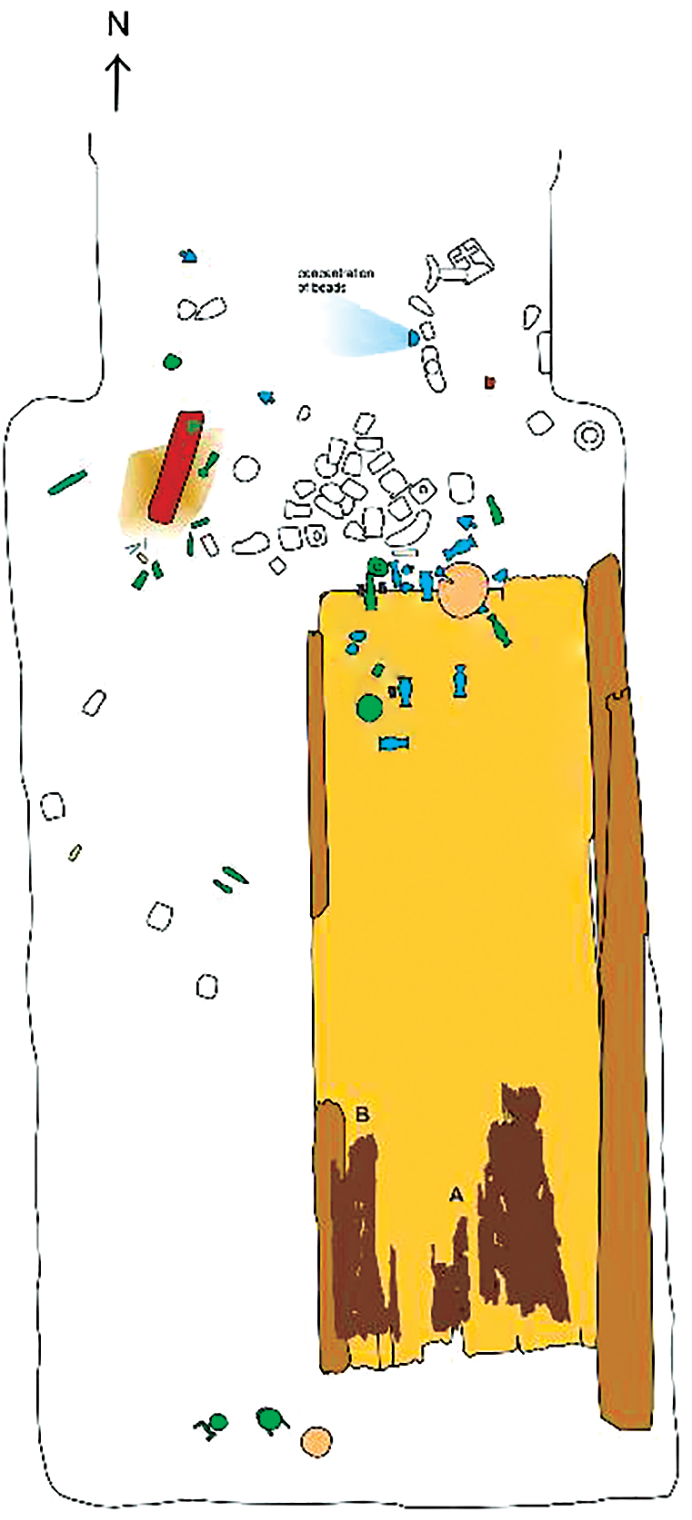

Fig. I. Burial chamber of the lady Ankh, with coffin bottom in situ and location of fragments A and B. (Drawing by Gina Criscenzo-Laycock) ${ }^{6}$

consists of wood fragments numbered as 1413/59 and $1413 / 56$. The smaller, westernmost (1413/54) fragment B was located immediately beside the back of the coffin. We designate this coffin by the siglum B4B (patterned on the coffin designations devised in A. de Buck's edition of the Coffin Texts $^{7}$ ).

Parts A and B were conserved and restored by Mohamed Sayyid in March/April 2017. The positioning of the pieces was established by a detailed study of the excavation photographs, the textual content, and other decoration. In this way, an accurate positioning was achieved between

\footnotetext{
${ }^{6}$ I express my gratitude to Gina Criscenzo-Laycock for producing this drawing, and to Toon Sykora for adding the decorated coffin surfaces A and B.

${ }^{7}$ For an updated list of coffin sigla, see H. Willems, Historical and Archaeological Aspects of Egyptian Funerary Culture: Religious Ideas and Religious Practice in Middle Kingdom Elite Cemeteries (CHANE 73; Leiden, 2014), 230-315.
} 


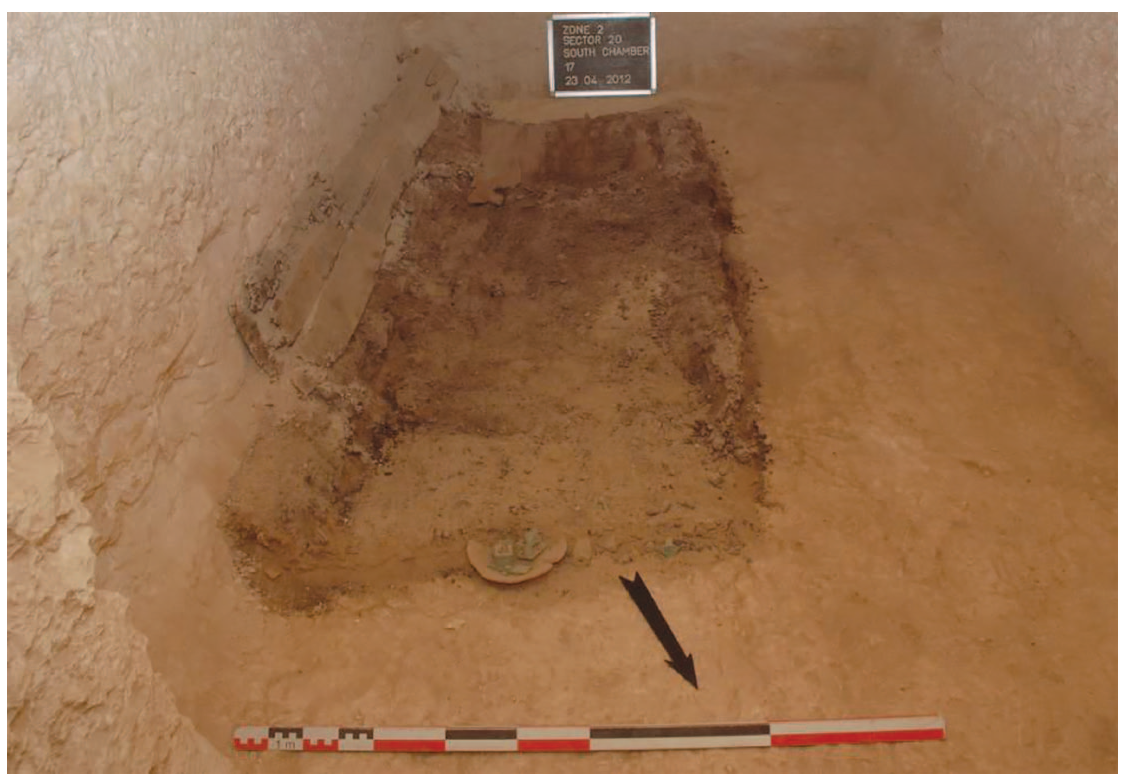

Fig. 2. View of the bottom of coffin B4B still in situ, with some of the surrounding burial equipment still in place. Foot end at rear.

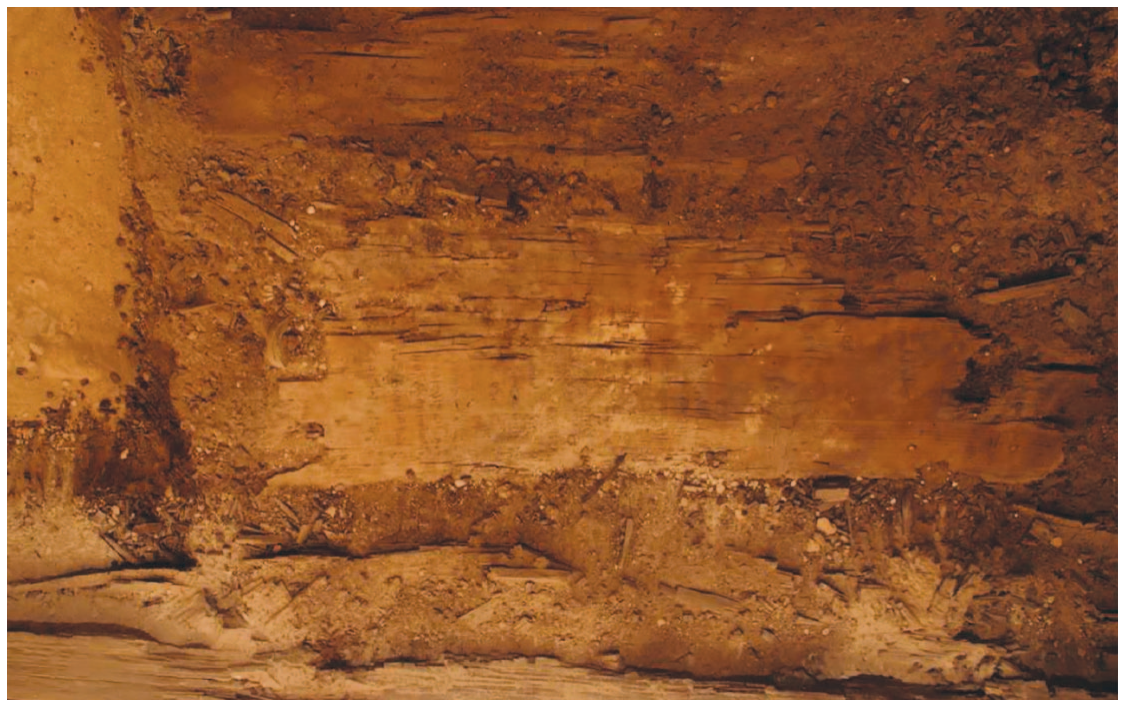

Fig. 3. Detail of the area near the foot end of the bottom of B4B. The large part in the centre of the image (I4I3/59 and I4I3/56) has been designated as part $A$, the small one at the top $(1413 / 54)$ as part $B$.

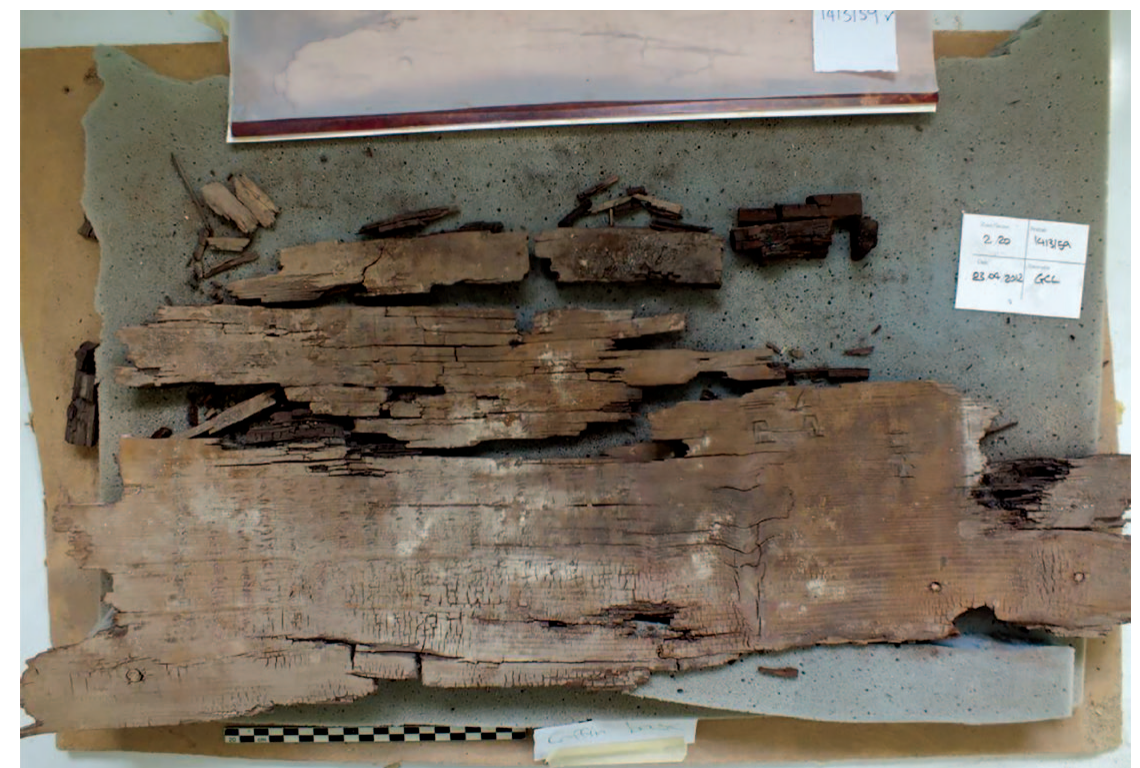

Fig. 4. The fragments of $1413 / 59$ (lower part of part A) after removal from their protective cover. 
$1413 / 59+56$. The pieces were then mounted on a backing, after which the relative positions of 1413/59 and 1413/54 were determined. Sets of photographs were processed using Agisoft Photoscan software by Kylie Cortebeeck, resulting in the orthophoto of 1413/59+56 (part A) (fig. 5).

On most pieces of the coffin, all traces of paint and ink have now disappeared. Amounts of CT have survived, but most are in a very poor state. As was common in the early Middle Kingdom at Dayr al-Barshā, these texts were first inscribed in ink on the wood or on a thin plaster layer. Subsequently, these texts were made 'permanent' by engraving them into the wood. ${ }^{8}$ However, after the disappearance of the coat of plaster and whitewash and the ink it bore, only the deeper parts of the scratchings remain, and these hardly ever result in a legible text. The bottom part is in a slightly better state, as ink and paint are preserved in many places, even though the remaining traces are extremely vague and nearly illegible to the naked eye.

In preparing this study we have constantly worked on the original, where the use of raking light brought out even the minutest scratchings, but we also used excavation photographs, showing the object still in situ, and high-resolution photographs processed with DStretch software. ${ }^{9}$ DStretch enhances colours, and for this reason it is increasingly being used in epigraphic work. However, it should be pointed out that the software enhances the colours, not of the original object, but of the photographs of the object that the researcher is using. This means that an area where surface relief leads to a dark shade in the image will result in a less useful image enhancement for this particular area. Therefore, in the course of our work, part of the process consisted of continually re-photographing details with different lighting, which sometimes led to a better result. Accordingly, no single DStretch image offers an optimal image quality and DStretch images should never be used as substitutes for an epigraphic drawing. ${ }^{10}$

Parts A and B contain different texts. This is certain because in part $\mathrm{A}$, the complete height of a number of text columns is preserved. The CT inscribed in part B moreover show smaller signs that are unevenly distributed over the available space. These texts must be labels to depictions of which very few traces now remain. Despite the fact that the texts of part B have hitherto defied identification, it is nevertheless possible to make some suggestions about the nature of the decoration programme. Clearly the text design on the eastern half of the bottom differs from that on the western half. Put differently, the

\footnotetext{
${ }^{8}$ Cf. H. Willems, Chests of Life: A Study of the Typology and Conceptual Development of Middle Kingdom Standard Class Coffins (MVEOL 25; Leiden, 1988), 44, attribute 252; the occurrence of this attribute on Dayr al-Barshā coffins can be gleaned from p. 73, table 2 .

${ }^{9}$ For information on this Open Access software, see http://www. dstretch.com/.

${ }^{10}$ For the same reason, the DStretch images were in this case hardly useful as a basis for making line drawings of the outlines of the surfaces inscribed with ink. For this reason, and to my regret, this information is not provided in fig. 9.
}

bottom was divided into two halves along the vertical axis. This fact in itself strongly suggests that Ankh's coffin was inscribed with a Book of Two Ways, which almost always displays such an arrangement, and which at Dayr al-Barshā was customary on the bottom. The Book of Two Ways covers CT spells 1029-1185. ${ }^{11}$ Closer inspection confirms that the bottom did indeed contain this composition. The right hand part of part A on fragment 1413/59 shows traces that are not easy to recognise with the naked eye, but which come out very clearly in the DStretch image as a barque on a sledge (fig. 6). This is the vignette to CT spell 1128. On many coffins this is followed by spells 1129 and 1130. The former of the two frequently appears above 1128 , in an area not preserved in coffin B4B. Then follows the famous spell 1130, which is almost completely preserved there. The line drawing in fig. 7 renders the incised outlines of the hieratic texts and the paint remains of the vignette of CT spell 1130.

The arrangement in B4B, with the eastern half of the coffin bottom ending near the foot end with the sequence 1128-[1129?]-1130, is common at Dayr al-Barshā. ${ }^{12}$ In these coffins, the western half of the coffin near the foot end usually bears a selection of spells from the sequence 1074-1094. Many take the form of depictions accompanied by labels. This confirms the suggestion already made earlier that part B might be made up of scenes accompanied by labels. However, I have been unable to match the traces with any part of spells 1074-1094. The present article will therefore restrict itself to spells 1128 and 1130 .

\section{Spell I I 28}

The right hand part of 1413/59 preserves parts of CT spell 1128 including its vignette (a barque on a sledge). It is poorly preserved in $\mathrm{B} 4 \mathrm{~B}$, but it closely resembles the rendering in B4C (see fig. 8). In that coffin, the lower part is a sledge with a falcon head, which carries a barque with a canopy and two steering oars. The scene is framed left and right by a thick, vertical line. The colours in B4B are different: red as opposed to white and some blue in B4C, but one can clearly recognise parts of the sledge, two poles to which two steering oars are attached, and the vertical division line to the left of the scene (the one in front is not preserved). Two poorly preserved, black, slanting lines on the right might belong to the prow of the vessel. Other black traces occur further to the right, but I am unable to make sense of these. The red lower line of the sledge is best preserved on the left; further right, only traces of red remain. Where one expects the continuation of the lower line of the sledge, there is a dark, linear feature, which may be decayed paint. Since this is uncertain, this shape has been rendered in a different colour (light brown) in

\footnotetext{
${ }^{11}$ CT VII, 252a-521f [1029-1185].

12 See CT VII, folding plans $1-15$ at the end of the volume. On these plates, CT spell 1128 is referred to with the number 99, 1129 with the number 100 , and 1130 with the number 101 . The model of $\mathrm{B} 4 \mathrm{~B}$ recurs in $\mathrm{B} 1 \mathrm{C}, \mathrm{B} 3-4 \mathrm{C}$, and $\mathrm{B} 1 \mathrm{~L}$.
} 


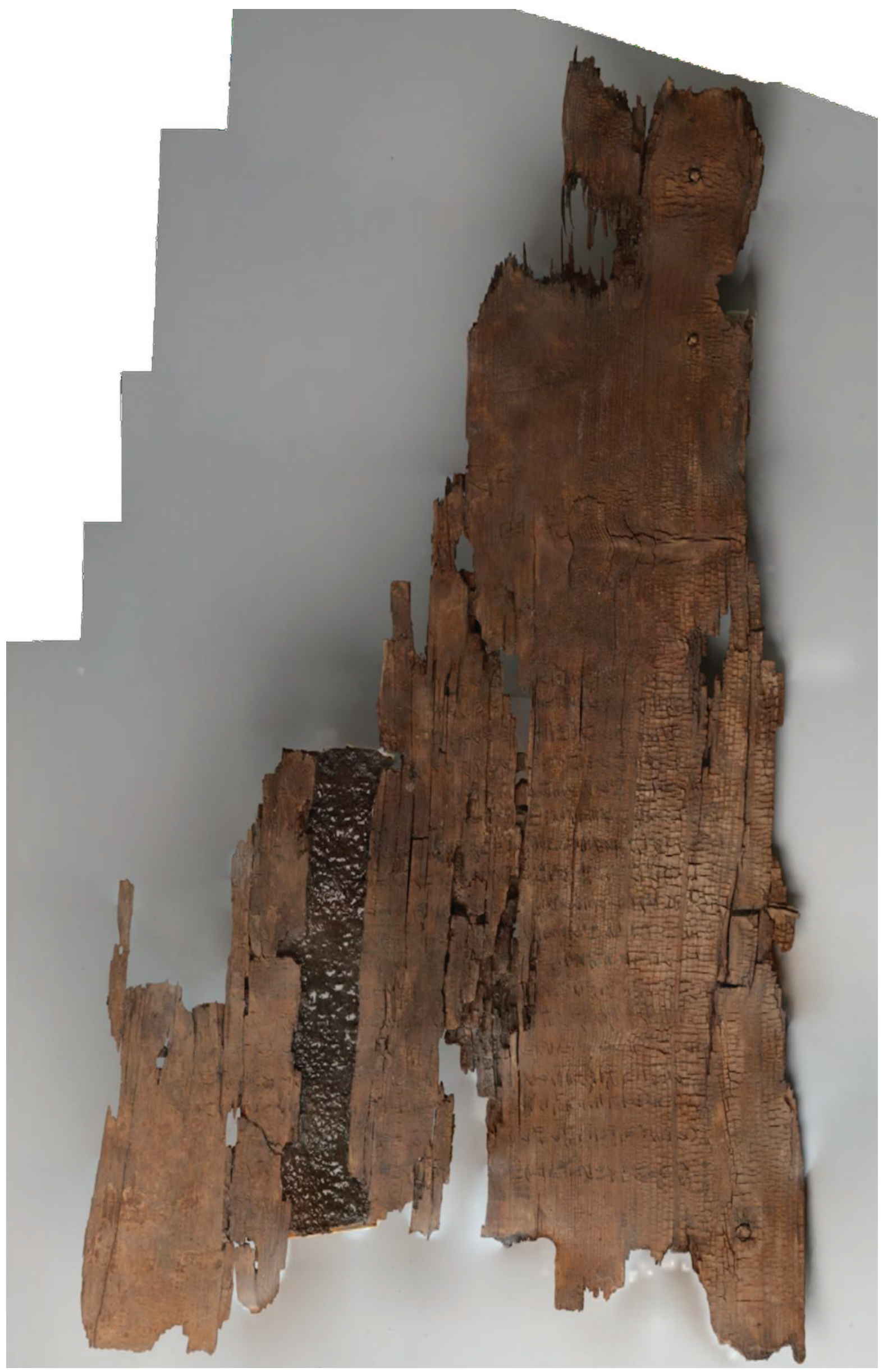

Fig. 5. Orthophoto of fragments $|4| 3 / 59$ and I4|3/54. 


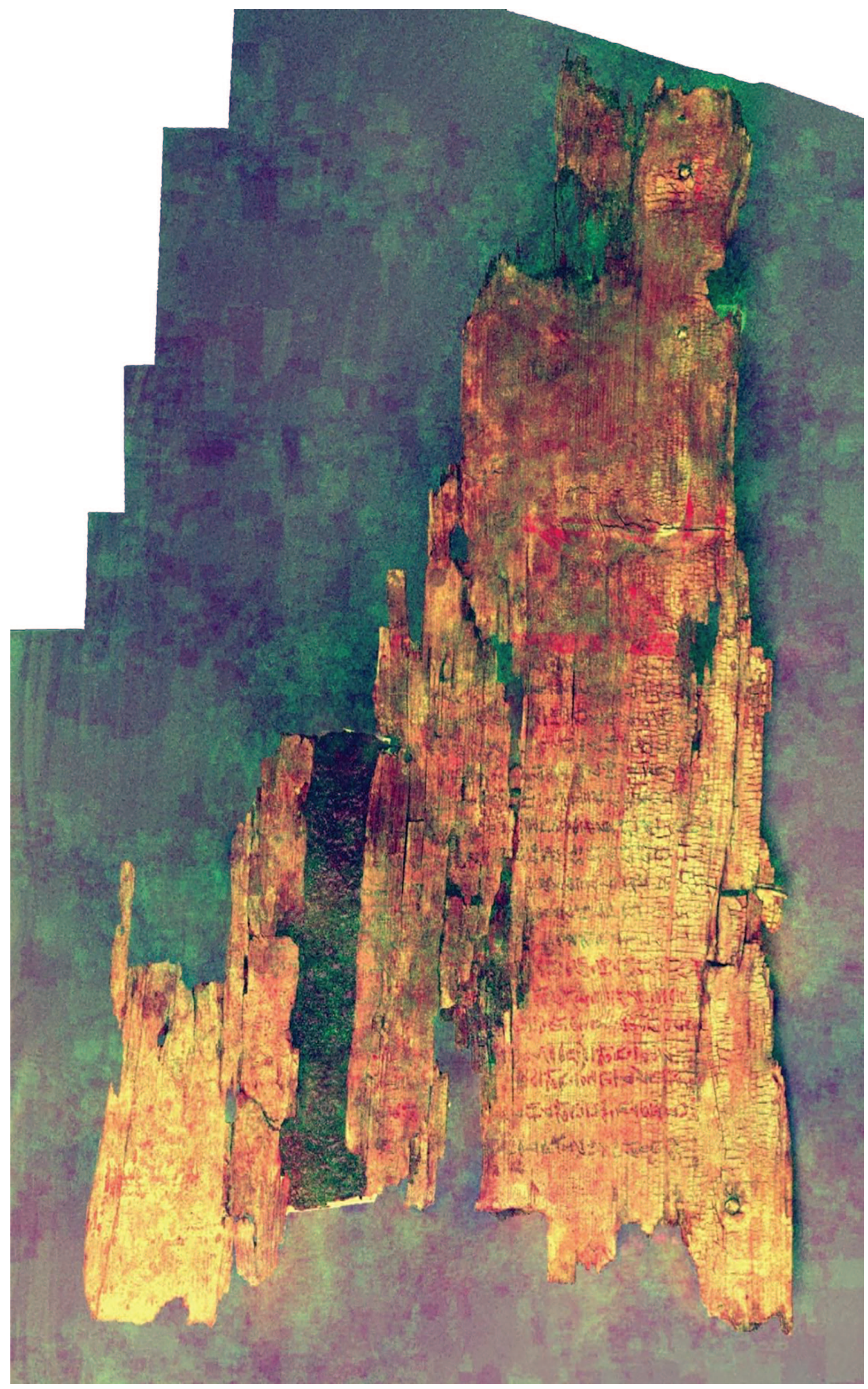

Fig. 6. DStretch image of the orthophoto of fragments $14 \mid 3 / 59$ and $1413 / 54$. The image shows clear remains of red and black ink. On the right, in red, remains are visible of the vignette of CT spell II28: a barque on a sledge. 


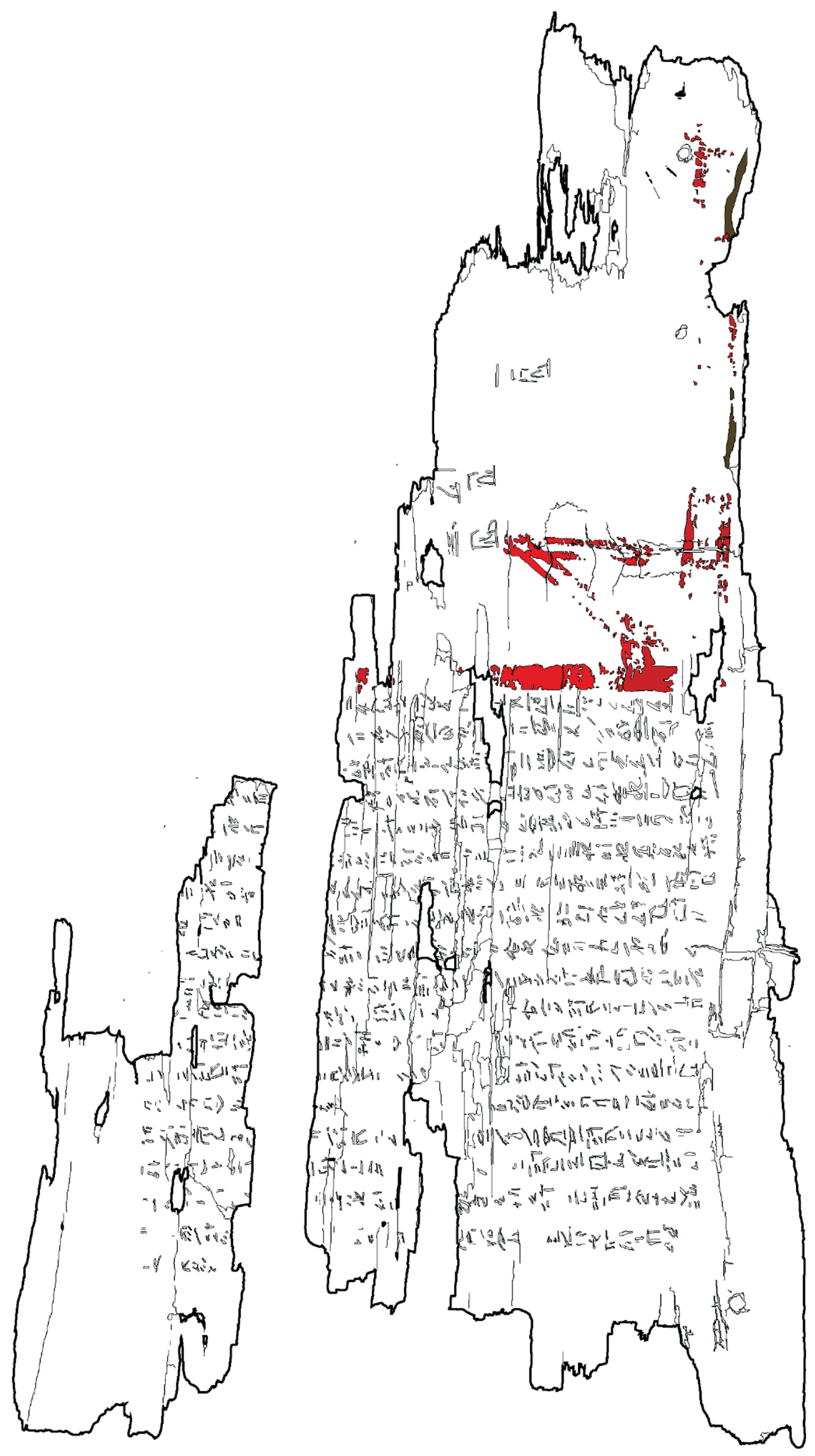

Fig. 7. Line drawing of fragment $A$ of the bottom of coffin B4B. 

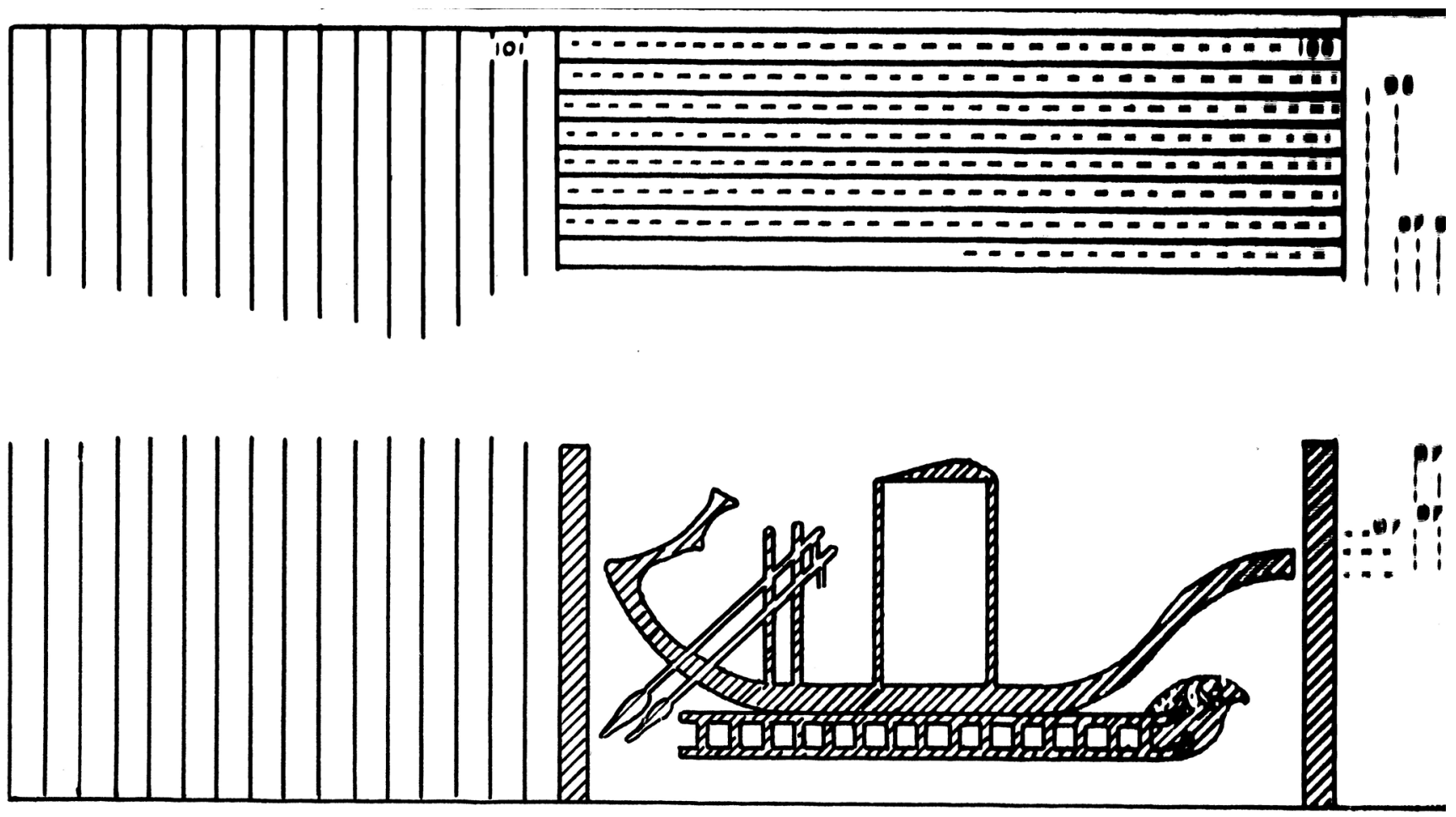

Fig. 8. The section containing CT spells II $28-1 \mid 30$ in coffin B4C, after CT VII, folding plan 3.

fig. 7. Higher up, there are similar traces, but not all of these offer a recognisable shape; these parts have not been rendered in fig. 7. Further to the right, another linear outline has been rendered in light brown, as it is clearly recognisable both on the original and in the DStretch image. However, it is unlikely to be the lower part of the sledge, as it has a wavy outline. Is it the tow-rope attached to the front part of the sledge, which is also rendered in the vignette in B1L?

Some labels, written in large hieratic signs, still accompany the vignette. The last two are easily legible: 'Hu' and 'Sia'. These deities are mentioned in CT VII, $458 \mathrm{j}-\mathrm{k}$ [1128]. The first label also refers to a deity, but the surface is badly preserved here. Preceding the divine determinative there is a t-ending preceded by a horizontal line. Probably, this line is the lower part of [ $[$. The resulting name 'Isis' occurs in CT VII, 458f [1128].

\section{CT spell I I 29}

Nothing preserved.

\section{CT spell I I 30 (see fig. 9)}

Col. 1: The top of the first column is missing over a length corresponding to approximately 12 squares. This space corresponds to the part between square brackets, which is based on how the parallels render the passage (published by de Buck in CT VII, 461c-e): [ $d d$ mdw in št3.w rn. Nb r $\underline{d}$ r $\underline{d} d$ hft sg]r.w nšn m skd.wt šnw.t (underlined part in red in most coffins). ${ }^{13}$ The first word of which traces remain on our coffin is $[s g] r . w$. Most coffins feature a longer text, but a similarly brief variant occurs in the (unfortunately only partly preserved) variant B3C. In the 2012 excavation photo, some wood surface remains before the currently first preserved sign $r$, but nothing is legible here. Unfortunately, these wood remains were not recognised during restoration in 2017.

$N \check{n}$ : on the photographs, only four horizontal lines are visible, but on the original, the sides of the $\check{s}$-sign are faintly visible. Skd.wt: of the first two signs, two vertical scratches and some ink remain. This must represent \&uIl/. The boat determinative at the end is not as clear in the photographs and DStretch images as on the original (scratchings and paint). The area in between is now lost, but was still present (although perhaps damaged) during the excavation. It is suf-

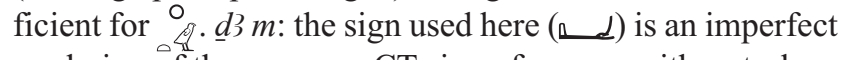
rendering of the common CT sign of an arm with a stroke.

The last legible sign in the column is the $h t p$-sign. There is sufficient space below this for the phonetic complements $t$ and $p$. Close inspection of this area revealed no evidence that anything was ever written here.

Col. 2 (CT VII, 462b-d [1130]): At the beginning of the column, the same length of text is missing as in column 1.

\footnotetext{
${ }^{13}$ Note that both here and elsewhere, the reconstructed text in areas that are not physically preserved (rendered between square brackets) can only be suggestions for how the text could be reconstructed, based on what the parallels offer and on considerations of space. Writing question marks in all these cases would not contribute to the legibility of the rendering.
} 


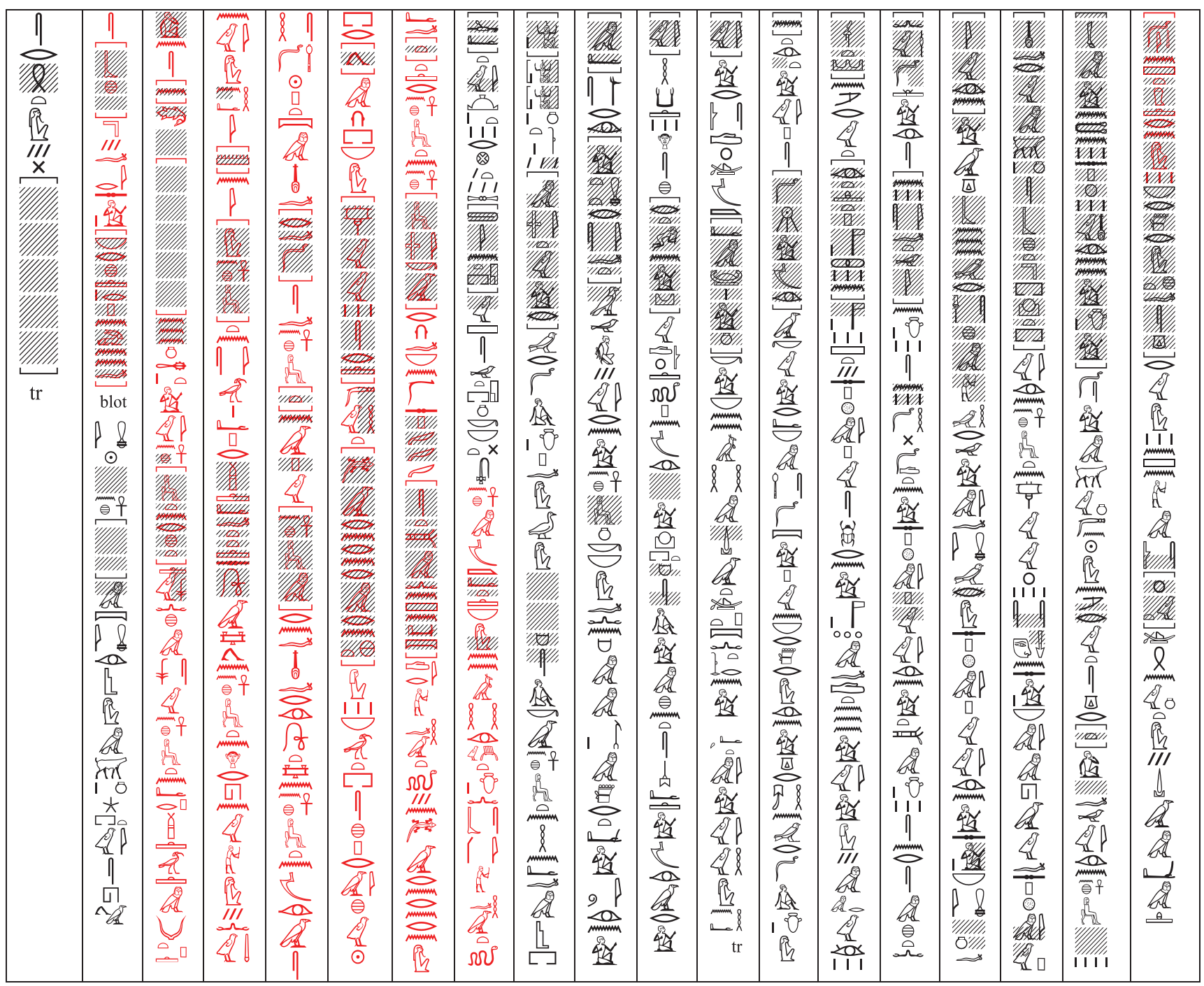

Fig. 9. Hieroglyphic transcription of CT spell II30 on coffin B4B.

This must correspond to [ $w h m=i / N n=t n$ sp 4 frr. w iri. $n=i$ $i b=i] d s=i$ (= CT VII, 462b [1130]). Above $\underline{d} s=i$, surface space sufficient for half a square remains, but nothing is legible here. Of the word $h n w$ the sign $\mathrm{rr}$ is clear. Traces below it seem to show an of on the left, and two curved scratchings on the right, which must represent a hieratic 0 written unusually high to the right of the bird. Below the sign $\odot$ is clear on the original, ${ }^{14}$ though less so on the photographs. Below that I see an unclear sign resembling a bird (see fig. 7), but this does not correspond to anything in the published text of the parallels. I have also thought of the sign A40 (sitting god), but this is not written in quite the same way elsewhere on the coffin. Because nothing else suggested itself, I have inserted this latter sign in the transcription, but I feel uncertain about it. The surface for the word n-mr.wt was still preserved when the excavation photograph was taken, but only 7 is now legible. Today, the

\footnotetext{
${ }^{14}$ In the CT edition, de Buck uses a sign looking like (O. The hieratic form in B4B does not suggest that the small dot in the centre is a small circle (see fig. 7), and for this reason I have transcribed the sign as N5.
}

lower part of the last sign is lost, as are the signs 4 below (no wood now preserved). On the excavation photo, however, the $w$-quail is faintly but clearly visible. The $\square$ below is easily recognisable in the original.

In the published text this is followed by sgr.t isf.t. In some versions the first word reads $s g r$. The $g$ sign was clearly written in ink, but the scratches only partly correspond to the ink traces. Although no $t$ is preserved after $s g r$ in $\mathrm{B} 4 \mathrm{~B}$, the space between the $r$ and the determinative $\mathrm{A} 2$ is so large that it must have been there. Below it, where the

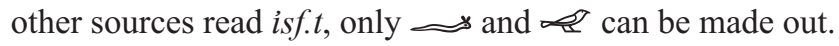
Preceding this, some indistinct traces (ink and small scratches) must represent is. After iw iri.n $n h$ there is a damaged surface space of about one square, followed by the clearly preserved numeral ' 4 ' (seen in the original). This must correspond to the end of CT VII, 462d, and the lacuna can only have contained the word $s p$ spelled $\overrightarrow{O \square}$, although B4B usually writes this word $\overline{\mathrm{Q}}$.

Col. 3 (CT VII, 462d-463b [1130]): At the beginning of this column, as in the preceding columns, a length of about 12 squares has disappeared, which must have contained a 
rather widely spaced writing of the text $n f r . w m-\underline{h} n w$ sbh.t 3h.t. The first word of CT VII, 463a is given in the published variants as either ssn or snsn. Before the bottom was removed from the tomb, the wood surface was preserved here, although creased by cracks. Today, the central part has broken off. Of the top group, two verticals remain, which could be $\|$ I. In the lower group, another vertical, perhaps $\sqrt{\text {, }}$, followed by the clearly legible sign (fully clear in the preserved ink traces; the scratches only render the two horizontal lines representing the eye). The end of the line is not clear in the photographs, but the original allows the reading sp im $p w$. The lower part of im is lost, and only the right hand part of the $p$ and the baseline of the $w$ now remain.

Col. 4 (CT VII, 463c-f [1130]): At the beginning of the column, a surface length of about four and half squares has disappeared, of which the lower end contained the top part of sign A1. The surface must have contained a rather widely spaced spelling of $i w$ iri. $n=i$. Iw iri.n ' $n h$ th would fill the lacuna better, but the first traces preserved in no way accommodate the $n$ of $t n$. If the demonstrative pronoun $t n$ was omitted, there should be the name of the deceased; here one would expect the sitting-man-on-throne determinative of the name ' $n$ h, which certainly was not there. The restored formulation in the first person singular is therefore certain. The part in square brackets of $3 g[b w r s h m]$ is lost; only part of the hind leg of the determinative ${ }_{\mathrm{h}}^{+}$of $s \mathrm{hm}$ is preserved. In the word $s$ 'man', the $s$-sign and the determinative stroke are clear. In front of the stroke there are no clear scratches, and only vague ink spots. In view of the available space, the abbreviated hieratic form of the sitting man determinative (A1) must have been used, which otherwise only occurs in column 18. At the place of $s n-n w$, only an indistinct scratch, possibly of 0 , located in the left half of the column, could be made out.

Col. 5 (CT VII, 464a-d [1130]): In the publication, this is followed by $n w \underline{d}=i / N$ iri.t/iri $i=$ sn isf.t in $i b=s n$ h $\underline{d} \underline{d} d$.t. $n=i / N$. The first remaining trace, on the left of the column, is probably the tail of the $\underline{d}$ of $w \underline{d}$. The ink traces of the verb iri are clear, but only part of this hieratic outline (the pupil) was scratched. In this line and the next, such cases of the hieratic signs not having been incised are increasingly common. For instance, in this column, only part of the heart-sign was scratched in outline. Of the suffix $=s n$ after $i b . w$ only the $s$ remains; where the $n$ would have been there is a crack in the wood, and the plural determinative (for which there is ample space), is not visible, except for a vertical scratch that must correspond to the central line of the plural strokes; of the others, however, there is no trace. The scratches outlining the suffix $=i$ in iri. $n=i$ contain an error: the raised arm of the sign curves upwards at the right, as a result of which it resembles sign A2 rather than the required sign A1.

Col. 6 (CT VII, 464d-465a [1130]): At the beginning of the column, a small part has broken off, which must have contained the word imn.t 'West'. Based on the published parallels, the phrase $s h p r . n=i$ should occur in the middle of the column. The $s$ is well preserved, the space below it would be sufficient for $\stackrel{\ominus}{\stackrel{\ominus}{2} \text { or }}$; the ink traces and scratches at the top seem to render a weightier sign, making the latter reading more likely.
Col. 7 (CT VII, 465a-c [1130]): Based on the parallels, the line should be opened by $n$.t ir.t=i. The $t$ and the eye can be made out; in the space below there must have been a $t$ and a determinative stroke, but only the $t$ can be recognised. The top of the of $m 3 . k w$ has now broken off, but in the excavation photograph the remaining surface for the complete sign seems still to be present. In $r^{c} n b$ I could find no trace of the expected sun determinative. The sign $\rho$ is partly broken off. The remaining traces suggest a rather more irregular, vertical sign.

Col. 8 (CT VII, 465a-466b [1130]): At the beginning of the column, the particle $i w$ is not preserved. There is ample space for the preposition $r$ in $[i w]=i r s k d$, and although I have found reliable traces of this sign in the original, these cannot be made out either in the photograph or in the DStretch image. The expected sign group was seen in the original, but neither the traces visible in the photograph nor in the DStretch image fit this reading. Nothing was rendered in fig. 7.

To the left of the $k$-sign (in ink $n b n n h h$ ) there is a deep scratch slanting down to the left. This does not seem to correspond to any sign, and is probably an error on the part of the scribe.

The free space between $t r . n=i$ and $\cdot . t$ is unusually large.

At the left end of the line, there are some tall, narrow signs. After $h n^{r}$, almost all versions read the divine name 'Heka', which in this source, however, appears at the top of the next column, preceded by a damaged area that probably contained the particle $i w$, an arrangement otherwise only attested in B6C. In this latter source, $h n^{r}$ is followed by the name of the coffin owner. The traces and available space in B4B do not support such a reading. However, there could have been the first person singular suffix referring to the deceased (cf. B4C); the transcribed scratch traces could fit that sign. The evidence is not sufficiently strong to warrant transcribing that word here, however.

Col. 9 (CT VII, 466b-e [1130]): The start of column 9 as far as it is preserved is approximately one square lower than the top ends of the columns further left. In variant B6C, the particle $i w$ occurred in this location, and it probably stood here as well. After $D w-k d$, the demonstrative pronoun is certainly $p n$ (the $n$ being only recognisable in ink; apparently it was not scratched), rather than $p f$, as in all published parallels. Below the horizon sign, the reading is not very clear. On the right, there is a blot of black ink, on the left, two vertical signs crossed at the top by two short, slanting lines. Is this for $\square \square$ ? Below, there is a horizontal line that does not seem to correspond to anything in the published versions of the spell. Note that this area was still complete when the excavation photograph was taken, but that a large piece of wood has now disappeared. Immediately below the break, a vertical sign, which must be an $s$, can be seen. At the end of the column, the last signs of $m 3 r$ are not clear. What has been transcribed as $\prec$ rather looks like 2 . At the end there seems to be an A1. The expected sling-sign is not there.

Col. 10 (CT VII, 466e-467e [1130]): After the end of column 9, one expects $m^{-}{ }^{\top}$ wsr iri=i mi.t.t $r$ isf.tyw. The 
missing space at the top of the column, where $m$ - $^{\text {? }}$ should have been, is just large enough for this group. After wsr, all published parallels feature the sign , but in coffin B4B the available space is too small for this if the subsequent passage is reconstructed, in line with almost all other variants, as iri=i mi.t.t $r$ isft.y.w. Therefore, our transcription omits this sign. If, however, B4B had a shorter text here, like mi.t.t isf.ty. $w$ in $\mathrm{B} 4 \mathrm{C}$, there would be space for 厎.

Below isf.tyw, all sources have the text $i w n=i{ }^{\ulcorner} n h / i w$ ' $n h$ h $N$ pn. In B4B, the readings are obscured after the particle $i w$ by numerous scratches that concord ill with the published text. However, the key word of the passage is the word ' $n h$ 'life', which is also the name of the coffin owner. It seems the text was accordingly adapted into $i \mathrm{w} r n=i{ }^{\complement} \mathrm{C} h$. I was at first inclined to translate this as 'my name is Ankh', and for this reason I interpreted the unclear traces after it as the enthroned-man determinative. However, since nominal clauses are never preceded by the particle $i w$, this can only be a pseudoverbal construction 'my name has come to life', and here the determinative would not fit. The traces nevertheless fit this reading best. I assume that this determinative, so ubiquitous after the name Ankh on this coffin, was inadvertently written.

Of the subsequent part, the surface is no longer well preserved now, but traces, also in the excavation photograph, suggest ink. At the bottom of the column follows the phrase iw iri. $n=i$, which all variants have in this location. Note that the traces of $i w$ do not allow the transcription of that is otherwise prevalent in this manuscript, but only the uncommon of.

Col. 11 (CT VII, 467e-f [1130]): h.h.w m/n.w rnp.wt m-im. $y t w=i$ : In coffin B9C, the first word is written with a vertical sequence of three heh-signs. The surface where the first heh-sign would have been in B4B has broken off. Below it are three sign groups of which each has an ideogram stroke on the left. In each of the three, the rightmost part is heavily damaged, but since below them the word rnp.wt follows, this part should contain hh.w $\mathrm{m} / n . w$. The lowermost of the three sign groups in fact closely resembles IO. Quite conceivably, the two others would each conceal a heh-sign. The remaining traces of the topmost one would fit the baseline of the sign and the raised arm on the left. In the second group, the raised left arm of the sitting man is also visible. Each of the two sign groups can be transcribed as ,

The determinative of $w r \underline{d}$ in $w r \underline{d}-i b p f$ has been written only in ink; its contours were not incised. I originally thought the ink traces render a divine determinative A40, but it is rather the tired-man sign. The determinative A40, which is partly preserved, apparently occurs after $p f$. The traces after that are very unclear. A hook-like fragment may be the duck-sign for 'son'. What follows is unclear in the excavation photos and the wood surface is now gone. Since the reading could be either $s 3 G b$ and $s 3 N w . t$, no certain reading can be suggested.

Further down, the name of the deceased, with the determinative of the man seated on a throne, seems to be followed by the demonstrative pronoun $t n$, as elsewhere in the text.

Col. 12 (CT VII, 467f-468e [1130]): After the text at the end of column 11, B1C and B1L read $w^{\top} . t$ iw iri. $n=i$ i3.wt r niw.wt ts $p$ hr. At the beginning of column 12, however, there is no space for the entire part before the underlined passage in the citation. I therefore assume our source had a version similar to $\mathrm{B} 3 \mathrm{C}$ and $\mathrm{B} 4 \mathrm{C}$ : iw i3.wt $r$ niw.wt. The sign niw.t was written in ink. Subsequently, only the upper curve of the sign was incised.

The $k$ of ink was not incised; the surface in the area where $s$ d.t was written is not well preserved, and hardly any clear scratch traces were recognised. From here on until the middle of column 18 the text is written in red: ' $n h m m 3^{\top} . t n b n$ $n h h$. This whole area was still relatively intact during the excavation, but now the phonetic complement of ${ }^{2} n h$ and the subsequent words (as far as $n h h$ ) have broken off. In the excavation photo, some signs are faintly visible: $\smile$, $\checkmark$, the top of the god determinative, and the genitive $n$. Since the text was preserved when found, the transcription is based on the photograph. Below $n h h$, the text is well preserved.

Col. 13 (CT VII, 468e-469d [1130]): The area of the first $t$ of eft.t has broken off. At the beginning of the passage corresponding to CT VII, 468f, the name of the deceased occurs, of which the determinative is not preserved. It is uncertain whether the second occurrence of the name was followed by the demonstrative pronoun. Since the column would be slightly longer than the preceding columns if $t n$ would be restored here, I have left it out in fig. 9. I have hesitated about the transcription $\cap$. The rounded top seems to rule out the $p r$-sign.

The reading of the word $n s p . w$ following $n b$ is problematic. At the top, there are four horizontal lines, of which the second and third are connected by an incomprehensible scratch; perhaps this represents a meaningless ligature line. The only way to explain all these lines is to assume that (1) different from all parallels, version B4B did not read the direct genitive $n b n s p . w$, but the indirect genitive $n b n n s p . w$; and that (2) the group $n s$ is here written $\bar{\Gamma}$, unlike the parallels published in CT VII. Below this there are five oblique lines. Version B1L has a reading that cannot fit our text, and the other sources lack this particular passage or have a lacuna, with the exception of $\mathrm{B} 3 \mathrm{C}$, which reads not fit the traces in B4B either. I assume that the five oblique lines originally were, or should have been, six, each pair of lines representing the sign $\rightleftharpoons$ (cf. Möller sign 441).

The restored text after nsp.w, stm nšn, has been taken over from $\mathrm{B} 1 \mathrm{~L}$, the only coffin where this passage is complete.

Col. 14 (CT VII, 469d-f [1130]): The determinative of the verb pri is unrecognisable but there is space for it. The faint traces of mhw.t have been observed with certainty in the original, even though, due to the very rough surface of the wood in this area, they do not come out well in the photograph. Nothing is visible of the words $\underline{t} 3 w . w s r$ and $\breve{s} 3 r n . w$ m r $n$ ps $\underline{d} . w t$.

Col. 15 (CT VII, 469f-470a [1130]): Beginning of column preserved. The determinative of $s \underline{h} \underline{d}$ consists of merely two horizontal strokes, which cannot be the normal determinative (sun with rays), but at best only the sun disk. According to the published text, the lacuna after $n f r$ should be filled 
with $r, f$ and $\underline{d}$. However, the intervening space is somewhat too large for this. Therefore one might consider the possibility that, instead of $n f r$, this version originally had $n f r . w$, which would well fill the available space.

Where the demonstrative pronoun $t n$ would have been after the first mention of the name of the deceased, only part of the scratched $n$ now remains, although the ink traces are more extensive. After 3, the published versions have $p w$. The $p$ is on the edge of a break; but here, on the right, there is a very short, vertical stroke, which could belong to the $p$. In the excavation photograph, the surface bearing the $w$ is preserved below, and even though its reading is somewhat obscured by mud, the sign is legible.

The lacuna below can only be filled by assuming that the coffin had a version similar to $\mathrm{B} 3 \mathrm{C}$ and $\mathrm{B} 4 \mathrm{C}$, with a second mention of the name of the deceased. Different from all other versions, this is followed not by $m r n=f$, but by $[m]$ $r n=f n f r$. The rest of the column is very clear.

Col. 16 (CT VII, 470b-d [1130]): Beginning of column preserved. The $n$ of $h n^{\complement}$ and the $m n$-sign of 'Imni have broken off. After the lacuna that must have contained the name of the deceased, the first remaining trace is the demonstrative pronoun $t h$ after the name of the coffin owner. This is followed by a somewhat blurred sign group, which (taking into consideration the published parallels) is probably the particle is. After this, $3 \mathrm{~h} \mathrm{C} p r$ is clear. The $\mathrm{C} p r$ sign is hardly visible and, again, there seem to be no incisions. Underneath this, a separate small piece of wood was attached during restoration. It fits well technically, but I feel not entirely certain that the text of the part above really continues on it. If it is rightly mounted, there is a remaining trace of the expected scroll determinative of ' $p r$. Below it, space for some signs has broken off; the excavation photograph shows a cracked surface in this area, which must have contained the word ' ft.t. After this, the main wood fragment begins with a slanting line on the left, probably the tail of a bird, which the ink traces in some DStretch images suggest to be an 3. Then follows a damaged but recognisable $w 3 t$-sign followed by an indistinct scratch cut through a clearly written $\boldsymbol{\Lambda}$. This is followed by an $n$ sign not found in any of the published sources. The next traces are clear. The sign group I transcribed as looks like a face sign with a horizontal line below, but the line seems to thicken towards the right and to form a ligature with $h r$; it is therefore likely to be an $r$. But there is a slight possibility it could be an $n$ (cf. CT VII,470c [1130]/B3C).

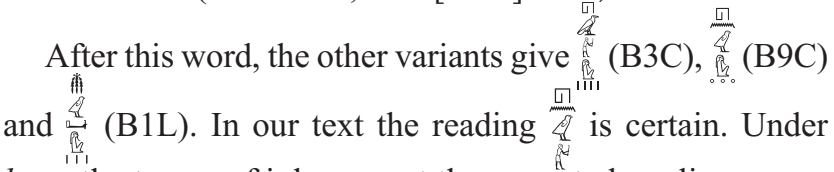
$h n w$, the traces of ink support the expected reading $\Omega$, but the scratches rather resemble a 'hieroglyphic' $t$-shape. Below it, on the left, the $w$ is clear. To its right, based on the parallels one expects a $m d w$-sign. No clear ink outline is visible here, and there are vertical cracks obliterating the inscribed surface, but a vague vertical incision remains.

Col. 17 (CT VII, 470d-471e [1130]): The first recognisable sign in the column is an $n$. Preceding it, B4C features the man-with-hand-to-mouth-sign. The raised hand of this latter sign is still visible in B4B. Below the $s$ a small fragment has broken off. This must have carried an $n$ and the upper part of the snd bird. In most published versions, the sign below is damaged or has completely disappeared. In B1L, de Buck reads the man sitting on a throne, but the remaining scratches in B4B do not match this. The vertical might correspond with the $h$ written in this place in B9C, but I do not understand the subsequent, indistinct traces. I have therefore chosen not to transcribe this. After this, two groups are completely lost, although the (cracked) coffin surface is preserved. This is followed by a lacuna in the plank of approximately $3 \mathrm{~cm}$. Because of the uncertainty over the beginning of the passage (is it the same as in the published versions?), no restoration can be proposed. The next wood fragment contains a series of three horizontal scratches and a small sign below. In one of the DStretch images, the latter sign has a round outline in ink, whereas the other signs are lines, perhaps not all of the same length. Based on the analogy of B9C, I assume this must be three water lines followed by a $n w$-pot.

After $\underline{h} . t=i$, the text normally continues with $i w=i r h . k w$ $s w n h m=i s w$ or $i w N(p n) r h . w s w n h m=f s w$. On this basis, the missing part of the text has been restored as $i w$ ' $n h$ [ $[t n$ rh.ti $s] w n h m=s s w$. Because the coffin belonged to a woman, I have entered a ti-ending after $r h$. As the text would otherwise be too short to fill the lacuna, it is likely that the full writing Pf of the verb form was used, not the common abbreviation $\square$. The wood surface on which Ankh's name must have been inscribed is preserved, but is rather rough; some legible ink traces remain only of the top part of the ankh sign and the $n$. Only one scratch, rendering the latter sign, remains. The group $n h m=s s w$ is clearly legible. Preceding it, matters are more difficult. I think I see a large $w$ to the left of a break in the wood surface. Possibly, this space contained the $s w$-sign. If so, the top of the $w$ is, however, crossed by another sign, perhaps the scroll of $r h$, explaining the transcription in fig. 9.

Col. 18 (CT VII, 471a-e [1130]): At the top of the column, two very faint vertical incisions where, according to the publication, one would expect the beginning of the word sbh.t, are likely to be an $s$. Of the subsequent group $b h$ nothing is visible. The end of the word is clearly made up of plural strokes followed by an $f$, for which $\mathrm{B} 9 \mathrm{C}$, which reads $s b h . w . t=f$, affords a parallel. Above $『$ some strokes occur where there should be a $t$, but the traces do not resemble this; for this reason it has not been transcribed. The next passage clearly reads ir $s$ (in which the 'man' determinative A1 appears in its abbreviated form, in this text otherwise only found in column 4). Following CT VII, 471c, $n b$ rh $r$ pn must have followed, filling a large part of the $3.6 \mathrm{~cm}$ long lacuna separating the two pieces of wood. This is followed in B1L by $w n n=f[\ldots$ (a god) $] m$ p.t. The first $1.4 \mathrm{~cm}$ of the wood surface retain no recognisable traces. Then follows a large blot of black ink. This is followed by $m i+$ a sign that could be $r^{r}$. Accordingly, we propose to reconstruct the available traces as $[w n n=f] m i R^{\ulcorner}[m p . t]$. Note that only mi $R^{\ulcorner}$survives, with $R^{\complement}$ not even being certain. As it is uncertain whether the ink blot was meant to obscure undesired text or whether it covers running text, the amount of text to be inserted is unclear. Starting with the ink blot, the text is in black. 
The traces in the space after 'Ra', where one would expect the divine determinative, are illegible. Immediately after it follow traces that seem to read the name of the deceased, 'Ankh'. But as remarked under col. 16, the piece of wood inscribed with this text may not actually belong here. This is further suggested by the fact that after the subsequent text break of about $1.6 \mathrm{~cm}$, the text continues with $m$ p.t, which must belong to the preceding passage concerning Re.

The determinative of the name of Osiris has been written in ink, but not scratched.

Col. 19 (CT VII, 471e-g [1130]): At the end of the column (which is much shorter than the others) there are some ink traces I was unable to transcribe.

\section{A comparison of the text variant of B4B with the variants on other coffins}

The early variant published here is important, as it sheds some light on the history of the Book of Two Ways. To date, only the variants included by de Buck have played a role in the study of the composition: B1Be, B1Bo, B2Bo, B4Bo, B1C, B3C, B4C, B5C, B6C, B9C, B12C, B13C, B1L, B2L, B3L, B4L, B1P, and B2P. Another version, considered by de Buck as too corrupt for inclusion in his edition, occurs on B17C. ${ }^{15}$ The three Boston coffins, datable to the rule of Djehutinakht IV or $\mathrm{V}$ were thus far the earliest ones known; they probably date to the very end of the Eleventh Dynasty or the beginning of the Twelfth. ${ }^{16}$ Coffin B4B, probably datable to the tenure of nomarch Ahanakht I, is at least a generation earlier and offers the earliest evidence for the Book of Two Ways currently known. ${ }^{17}$

De Buck recognised two different variants in the Book of Two Ways, which he called Group I (covering CT spells 1029-1130) and Group II (covering CT 1131-1185 + 10861087-1085). The corrupt version B17C iconographically belongs to Group II. Version B4L according to de Buck belongs to both groups. ${ }^{18}$ Table 1 offers an overview of which coffins belong to which group.

15 J. M. A. Janssen, 'De bodem van sarcofaag Cairo 28087', JEOL 15 (1957-58), 71-3 and pls IV-XII.

${ }^{16}$ Recent discussions of the date include R. E. Freed, L. M. Berman, D. M. Doxey, N. E. Picardo, The Secrets of Tomb 10A: Egypt 2000 $B C$ (Boston, 2009), 183-8; M. De Meyer and P. Dils, 'Fowl for the Governor: The Tomb of Governor Djehutinakht IV or V at Dayr al-Barshā Reinvestigated. I. Architecture and Archaeology', JEA 98 (2012), 57, with an overview of the literature.

${ }^{17}$ Still unpublished fragments of another Book of Two Ways were found in 2014 in a recent robber's dump in the tomb of Ahanakht I; these fragments may derive from a neighbouring tomb and are likely to be somewhat later. It is unclear whether the coffins of Ahanakht I in Philadelphia, which are still unpublished, contain a Book of Two Ways. Note that an early version of part of CT spell 1030, which is also part of the Book of Two Ways, has been observed in the pyramid of Merenre (I. Pierre-Croisiau, "Nouvelles identifications de Textes des Sarcophages parmi les "nouveaux" Textes des Pyramides de Pépi Ier et de Mérenrê', in S. Bickel and B. Matheu [eds], Textes des Pyramides et Textes des Sarcophages: D'un monde à l'autre [BdE 139; Le Caire, 2004], 268 and 278).

${ }^{18}$ CT VII, xvi.
Table I. Source groups of the Book of Two Ways according to de Buck (CT VII, xvi).

\begin{tabular}{lll}
\hline Group I & $\begin{array}{l}\text { Intermediate } \\
\text { group }\end{array}$ & Group II \\
\hline BI-2Bo, B4Bo, BIC, B3C-B4C, & B4L & BIBe, B5C, \\
B6C, B9C, BI2-I3C, BIL, B2L, & & BIP \\
B3L, B2P & & \\
\hline
\end{tabular}

Table 2. Source groups according to L. H. Lesko, The Ancient Egyptian Book of Two Ways (1972), 4-5; 134.

\begin{tabular}{llll}
\hline Group A & Group B & Group A-B & Group C \\
\hline BIBo, B4Bo, B3-4C, & BIL, B2L, & B2Bo, BIC, & BIBe, B5C, \\
B6C, BI2-13C, B4L & B3L, B2P & B9C & B4L, BIP \\
\hline
\end{tabular}

L. H. Lesko introduced a different grouping, based on the (non-)occurrence of the text units he recognised in different versions of the Book. ${ }^{19} \mathrm{He}$ distinguished between groups A, B, A-B and C (see Table 2). One notes that De Buck's Group I has been split up in Lesko's Groups A and $\mathrm{B}$, the latter being a variant of the former. He also identifies a Group A-B, which according to Lesko 'has affinities to both A and B'. ${ }^{20}$ Finally, de Buck's 'intermediate group', which solely consisted of B4L, has disappeared, with this coffin being entered both under Groups A and C, because it 'begins with the plan of the water and land ways according to version $\mathrm{C}$ and concludes with the plan according to version $A^{\prime} .^{21}$

Lesko claims that Group $\mathrm{C}$ is probably the oldest variant of the Book of Two Ways 'because the other versions seem to start with this version and by adding to it and by changing its orientation make it much more attractive to the people who wanted such a guide'. Group A according to him came next 'since version $B$ repeated the conclusion of section $V$ from both versions A and B'. ${ }^{22}$ This analysis is hard to understand, as it is not clear on which arguments Lesko bases his ideas about the direction of the text evolution. Moreover, the conclusion that Group C represents the earliest version has been proved unlikely both for reasons of content and because all of the pertinent sources date to the later Twelfth Dynasty. ${ }^{23}$

B. Backes' work on the Book of Two Ways only concerns CT spells 1029-1130 and therefore does not discuss de Buck's Group II or Lesko's Group C. His text-critical analysis does confirm the correctness of Lesko's distinction between Groups A and B, however. In his stemma, the formulation of Lesko's Group A depends on 'Vorlage $\gamma$ ', that of Group B on 'Vorlage $\delta$ '. There is only one point of disagreement: B2Bo, which Lesko assigns to Group A-B, clearly belongs to the

\footnotetext{
${ }^{19}$ L. H. Lesko, The Ancient Egyptian Book of Two Ways (1972), $4-5 ; 134$.

${ }^{20}$ Lesko, Book of Two Ways, 134.

${ }^{21}$ Lesko, Book of Two Ways, 139, n. 1.

${ }^{22}$ Lesko, Book of Two Ways, 134.

${ }^{23}$ W. Waitkus, 'Anmerkungen zur Verteilung der Dämonennamen aus TB 144/147 im "Zweiwegebuch", GM 62 (1983), 82; Willems, Chests of Life, 78 (on B1Be).
} 
Vorlage $\gamma$ group in Backes' stemma. ${ }^{24}$ Backes, in fact, disagrees completely with Lesko in identifying a Group A-B. After the removal of $\mathrm{B} 2 \mathrm{Bo}$, only $\mathrm{B} 9 \mathrm{C}$ and $\mathrm{B} 1 \mathrm{C}$ remain in this group, and Backes correctly protests that these two sources show great mutual differences. According to him, B1C is contaminated, whereas B9C is dependent on a source between the 'Urtext' and variant $\mathrm{B}$, or shows a contamination from sources dependent on both Groups A and B. He expresses a clear preference for the former interpretation. ${ }^{25}$

Despite its fragmented state, coffin B4B can be shown to belong to Group I/version A, but in the preserved part, which retains large parts of CT spells 1128 and 1130, it also overlaps with the intriguing coffin B9C. It is worth investigating whether B4B has greater affinities with the variants of Group I or with coffin B9C. The following is a list of the relevant passages.

CT VII, 461c-d: This passage is not preserved on B4B, but it probably occurred there. It is found both in B9C and in Group I/Vorlage $\gamma$.

461e: This is identical in all versions, but the orthography of B9C differs slightly from that in de Buck's Group I and $\mathrm{B} 4 \mathrm{~B}(\circ \circ \circ$ instead of the plural strokes). B9C and coffins B1C and B1L (the latter two belong to Lesko's Group B and are dependent on Backes' Vorlage $\delta$ ) have $\_$instead of the beating-man determinative found in B4B and Lesko's Group A/Vorlage $\gamma$.

462a: $\mathrm{B} 9 \mathrm{C}$ and $\mathrm{B} 4 \mathrm{~B}$ are the only coffins to write $\underline{d}$ 3 instead of $w d$ s. After this, all sources except B9C write the particle $m$. This latter element (the drop of an entire syntactic element only in B9C) suggests B4B is here more in agreement with de Buck's Group I/Lesko's Groups A and B/ Backes' Vorlagen $\gamma$ and $\delta$ than with B9C.

462b: B9C drops the element $\underline{d} s=i$ which de Buck Group I/Lesko Groups A and B/Vorlagen $\gamma$ and $\delta$ share with B4B. All these coffins and B4B here refer to the god Mehen; instead, B9C writes

462e: The word written $\underline{t} 3 w$ in $\mathrm{B} 9 \mathrm{C}$ is written $\underline{t} 3 w . w$ in de Buck's Group I/Lesko's Groups A and B/Vorlagen $\gamma$ and $\delta$ and B4B.

463a: The word written snsn in $\mathrm{B} 9 \mathrm{C}$ is written $s s n$ in Lesko's Group A/Backes' Vorlage $\gamma$ and arguably in B4B (see description of Col. 3, given earlier). In Lesko's Group B/Backes' Vorlage $\delta$, the only preserved source (B1L) has $s n$. After $s n b$, B4B features the adverb $\mathrm{im}$. This is absent in B9C, but present in one coffin of Lesko's Group A/Backes' Vorlage $\gamma$ (B6C). One source of Lesko's Group B/Backes' Vorlage $\delta$ has $i m=f(\mathrm{~B} 1 \mathrm{~L})$. Here, B4B therefore has the closest affinities with Lesko Group A/Vorlage $\gamma$.

463b: B9C reads sp 1 im pw; all sources of de Buck's Group I and B4B omit the 1. B4B here sides with Lesko's Groups $A$ and $B /$ Vorlagen $\gamma$ and $\delta$.

463c-e: This extensive passage is omitted in B9C. B4B here sides with Lesko Groups A and B/Vorlagen $\gamma$ and $\delta$.

464a: All sources write the phonetic complement $\underline{d}$ of $w \underline{d}$, except B9C. B4B here sides with Lesko's Groups A and $\mathrm{B} /$ Vorlagen $\gamma$ and $\delta$.

\footnotetext{
${ }^{24}$ B. Backes, Das altägyptische 'Zweiwegebuch': Studien zu den Sargtext-Sprüchen 1029-1130 (ÄA 69; Wiesbaden), 12, 53.

${ }^{25}$ Backes, Das altägyptische 'Zweiwegebuch', 12-13 and 45-9.
}

464b: B4B writes 'ib.w 'hearts' in the plural, similar to most variants of Group I; B9C uses the singular. B4B here sides with Lesko's Groups A and B/Vorlagen $\gamma$ and $\delta$.

464g: All versions of Group I and B4B write ntr.w as q. I I. B9C has a different reading. B9C exceptionally writes the water determinative of $f d . t$ 'sweat' as a water line with three dots below. All versions of Group I and B4B have the customary writing of three water lines. B4B here sides with Lesko's Groups A and B/Vorlagen $\gamma$ and $\delta$.

465a: The exceptional spelling of the word $r m \underline{t}$ in $\mathrm{B} 4 \mathrm{~B}$ ( ond half of Twelfth Dynasty). In the word rm.w.t 'tears', B4B and the coffins of Group I have the plural determinative, which is lacking in B9C. ${ }^{26}$ This is followed by a genitive, which is, in all sources except B4B, B9C and B1L (Group I) the direct genitive. B4B here sides with Lesko's Group B/Vorlage $\delta$ and B9C.

465b: $i w$ ps $[\underline{d}=i]$ in B4B is also found in B9C, but (with the variant $i w p s \underline{d} N$ ) seems also to have been the most common version in de Buck's Group I. B4B and B9C share the exceptional sky-determinative in the word shd; it is not found in coffins from de Buck's Group I.

465d: B4B reads $i w=i r s k d$ where most sources of Group I have $i w=i r$ skd.w.t. However, the Group I coffin $\mathrm{B} 6 \mathrm{C}$ also has $i w=i r s k d$. It is possible, but not certain, that $\mathrm{B} 9 \mathrm{C}$ also has this reading.

465e: Many differences in the variants on points of detail. No version has exactly the same reading as B4B, but all are closely similar.

466a: B4B and B9C read $n$ tr. $n=i$, a reading not attested with certainty in any Group I source; but the majority of these sources are much damaged at this point.

466b: The name of the god Heka does not carry the divine determinative in B4B. Although most coffins (including B9C) do have this determinative, B1Bo of Group I has the same reading as B4B. Some coffins of Group I provide the name of the demon $D w-k d$ with a scroll sign after $k d$, a reading also found in $\mathrm{B} 4 \mathrm{~B}$, but not in $\mathrm{B} 9 \mathrm{C}$. $\mathrm{B} 4 \mathrm{~B}$ is the only source where the demon's name is followed by the demonstrative pronoun $p n$. All other sources have $p f$ here. More importantly, in B4B, the name of the god Heka was probably preceded by the particle $i w$, preceding which the end of column 8 has illegible traces amounting to about one square. The closest analogy is offered by version B6C, which reads iw $H w h n^{`} N$ pn iw hlk $h r$ shr.t hft.y.w. B4B probably had the same text, but reformulated in the first person singular: iw $H w h n^{\Upsilon}=i$ iw $h k 3$ hr shr.t hft.y.w. Since $\mathrm{B} 6 \mathrm{C}$ is dependent on Vorlage $\gamma, \mathrm{B} 4 \mathrm{~B}$ has the closest affinities to this version.

466e: After the word $w \underline{d}^{r}, \mathrm{~B} 4 \mathrm{~B}$ has a scroll sign. This is absent in B9C, but present in several Group I sources. B4B has the closest affinity with Group I/Vorlagen $\gamma$ and $\delta$.

467e: The probable reading of hh.w n.w rnp.wt in $\mathrm{B} 4 \mathrm{~B}$ is closest to, but not identical with, the orthography in B9C.

\footnotetext{
${ }^{26}$ One reviewer of this article rightly pointed out that the plural strokes below the eye may in fact reflect a misinterpretation of the tears of the eye as plural strokes, an error that could be due either to the ancient scribe or to de Buck. If this is the case, there is no difference between B9C and the other sources.
} 
The spelling of $w r \underline{d}-i b$ in $\mathrm{B} 4 \mathrm{~B}$ is identical to that in $\mathrm{B} 3 \mathrm{C}$ and B4C of Group I/Vorlage $\gamma$.

468a: This passage is formulated as a verbal clause in $\mathrm{B} 1 \mathrm{C}$ and $\mathrm{B} 1 \mathrm{~L}$, which are dependent on Vorlage $\delta$; all others including B4B are formulated as an adverbial clause. In these latter, the sources dependent on Vorlage $\gamma$ feature the noun i3.w.t as the subject, whereas niw.w.t is part of the predicate. Only B9C reverses this. B4B here sides with Vorlage $\gamma$.

468b: All coffins of Group I/Vorlagen $\gamma$ and $\delta$ and B4B have a participial statement here; only B9C lacks the particle in. However, in $\mathrm{B} 1 \mathrm{C}$ and $\mathrm{B} 1 \mathrm{~L}$, which are dependent on Vorlage $\delta$, the clause structure (in $h w . t w \check{s}=s h w . t$ ) differs from those dependent on Vorlage $\gamma$ (in ḥw.t wšs hw.t). B4B here sides with the sources dependent on Vorlage $\gamma$.

468e: The determinative of the verb sbi and the clause structure (featuring the third person formulation with the name of the coffin owner) are identical in B4B and B3C, the latter being dependent on Vorlage $\gamma$.

468g-469a: The entire passage is absent in B9C but present in Group I/Vorlagen $\gamma$ and $\delta$ and B4B.

469g: Absent in B9C, present in B4B and most coffins of Group I/Vorlage $\gamma$. Although B4B here sides with Vorlage $\gamma$, it adds an otherwise unattested formulation by changing $r n=f$ 'his name' into $r n=f n f r$ 'his good name'.

470a: B9C deploys the $s d m . n=f$ form $m 3 . n=i$. The same form occurs in one Group I/Vorlage $\delta$ coffin (B1L), but B3C has the $s \underline{d} m=f$ form $m 3=s$ also found in B4B. B4B here sides with Vorlage $\gamma$.

470b: The spelling of $3 h$ ( B9C.

470e: B9C uses a negative subjunctive where B4B and the Group I coffins all seem to have a pseudoverbal construction. ${ }^{27}$ B4B here sides with Vorlagen $\gamma$ and $\delta$.

470f: The grammatical construction in $\mathrm{B} 9 \mathrm{C}$ is not clear; the reading of B4B finds a parallel in the Group I/Vorlage $\gamma$ coffin B4C.

471c-g: Although the passage is poorly preserved in $\mathrm{B} 4 \mathrm{~B}$, it is clearly a variant of the gloss in Group I; the version given by $\mathrm{B} 9 \mathrm{C}$ is different. The only coffins featuring this passage besides $\mathrm{B} 4 \mathrm{~B}$ are the contaminated variant $\mathrm{B} 1 \mathrm{C}$ and $\mathrm{B} 1 \mathrm{~L}$, which is dependent on Vorlage $\delta$.

This overview shows that in a few cases, B4B runs parallel to B9C, but wherever this occurs it concerns rather nondistinctive points, like the interchange of the synonymous determinatives $\multimap$ and with Group I. In some instances, it concerns highly relevant passages where B9C omits entire passages current in Group I. The association is particularly strong with the variants dependent on Vorlage $\gamma$. There is one important exception to this rule: the postscript of CT VII, 471c-g is thus far not attested with that group, but only with B1C and B1L. Since it concerns a long passage, one might argue that this instance somewhat neutralises the otherwise stronger association to Vorlage $\gamma$. However, it is well known that the transmission of postscripts and titles to Coffin Texts spells often diverges

\footnotetext{
${ }^{27}$ Assuming that in the case of coffin B4C the feminine stative ending was forgotten (as often happens in CT on coffins of women).
}

from the transmission of the main text. ${ }^{28}$ In the main text, the closest associations are between Vorlage $\gamma$ and B4B by far. $\mathrm{B} 9 \mathrm{C}$ remains an isolated case within the stemma.

The most important observations that can be made on this basis are:

(1) The postscript of spell 1130 (CT VII, 471c-g) was hitherto only attested in coffins from the time of nomarch Djehutihotep, dating to the second half of the Twelfth Dynasty (B1C, B1L). The fact that the same text already occurred in coffin B4B strongly suggests that this postscript was not a late addition, but already occurs on the earliest version now known. Since the postscript is attested in the sources dependent on both Vorlagen $\gamma$ and $\delta$, whereas $\mathrm{B} 9 \mathrm{C}$ (Vorlage $\beta$ ) has a different postscript, the postscript attested on B4B is likely to go back to Vorlage $\alpha$.

(2) The small remaining part of the bottom of coffin $\mathrm{B} 4 \mathrm{~B}$ is consistent with the redaction of group I of the Book of Two Ways, and more specifically with the tradition dependent on Backes' Vorlage $\gamma$. It is therefore likely that the rest of the coffin bottom was inscribed with (a selection of) the same group: CT spells 1029-1130. Therefore, this version was probably already current at the very beginning of the Middle Kingdom.

In terms of content, this version of spell 1130 has little to offer that is new. It only differs from those already known in two relatively minor points. In column 10 , the passage corresponding to CT VII, $467 \mathrm{~b}$ offers a divergent reading. The published versions read either $i w n=i$ ' $n h$ 'life belongs to me' or iw ' $n h n N$ pn 'life belongs to this $N$ '. In the present coffin, as remarked earlier (see p. 10) the version resembles the former of the two readings, but where the preposition $n$ is expected, there are two hieratic scratches too many. This means that the coffin can only read $i w r n=i\ulcorner n h<. w>$ 'my name has come to life'. However, where the grammatical structure required a pseudoparticiple of the verb ${ }^{2} n h$, one does not find the ending of the verb form (which of course can be omitted), but the determinative one expects after the name of the coffin owner. Since there is no other grammatically correct reading than the one I have just proposed, I assume that the scribe slightly adapted the text by alluding to the name of the coffin owner without effectively using it. The 'grammatically incorrect' determinative in this location could be a jeu d'écriture. This ploy allowed the scribe to establish an association between the textual content and the identity of the coffin owner.

Having injected the textual content with an allusion to Ankh's name, the scribe may subsequently have been

${ }^{28}$ This issue cannot be pursued here, but see, e.g. H. Hays, The Organization of the Pyramid Texts. Typology and Disposition (PdÄ 31; Leiden, Boston, 2012), 3-4. The fact that titles are secondary additions explains why they are very frequently omitted, and also why variants of the same spell can have different, occasionally almost 'individual' titles. A good example is afforded by the ubiquitous CT spell 225. 
inspired to a further sportive adaptation of the text. In CT VII $469 \mathrm{~g}$, the Group I versions B3C and B4C read $\mathrm{N}$ th 3 $p w \mathrm{~N} m r n=s$ 'This $\mathrm{N}$, this $\mathrm{N}$ is 3 by name'. In column 15, B4B offers a different reading: ' $n h$ tn $3 p w ' n h m r n=f n f r$ 'this Ankh, Ankh is 3 in his ${ }^{29}$ good name'. ${ }^{30}$ It is well known that Egyptians in the Middle Kingdom could bear two names: the full name and the 'nom d'usage social', which could be referred to as $r n=f n f r$ 'his good name'. ${ }^{31}$ In the present case, the divine name 3 is presented as the 'good name' of Ankh.

\section{Funding}

This research was supported by the Special Research Fund (BOF) of KU Leuven and the Research Foundation - Flanders (FWO).

\section{Author biography}

Harco Willems is a professor in the Department of Archaeology at $\mathrm{KU}$ Leuven and director of the archaeological project at Dayr al-Barsha (Middle Egypt). His main interest is the integrated study of ancient Egyptian social structure, administration and religion through combined archaeological and philological approaches.

\footnotetext{
${ }^{29}$ As frequently elsewhere, versions B4B shifts from the correct feminine form to the masculine form found in the Vorlage.

30 This reference to 3 'Egyptian vulture' as a designation of a netherworld being was missed in C. Leitz (ed.), Lexikon der ägyptischen Götter und Götterbezeichnungen, I (OLA 110; Leuven, 2002), 1, which, however, mentions other examples.

${ }^{31}$ P. Vernus, Le surnom au Moyen Empire: Répertoire, procédés d'expression et structures de la double identité du début de la XIIe dynastie à la fin de la XVIIe dynastie (StudPohl 13; Rome, 1986), 81.
} 